\title{
Mechanical and transport properties of concrete at high temperatures
}

\author{
Artur Galek, Harald Moser, Thomas Ring, Matthias Zeiml, and Josef Eberhardsteiner \\ Institute for Mechanics of Materials and Structures (IMWS) \\ Vienna University of Technology \\ Karlsplatz 13/202, 1040 Vienna, Austria \\ e-mail: \{artur.galek,harald.moser,thomas.ring,matthias.zeiml,josef.eberhardsteiner\} \\ @tuwien.ac.at \\ Roman Lackner \\ Material-Technology Innsbruck (MTI), University of Innsbruck \\ Technikerstraße 13, 6020 Innsbruck, Austria \\ e-mail: roman.lackner@uibk.ac.at
}

Keywords: Concrete, Cement paste, High temperature, Strains, Permeability

\begin{abstract}
When concrete structures are subjected to fire loading, temperature-dependent degradation of the material properties as well as spalling of near-surface concrete layers has a considerable effect on the load-carrying capacity and, hence, the safety of these structures. Spalling is caused by interacting thermo-hydro-chemo-mechanical processes with both mechanical and transport properties playing an important role. Within experimental research activities at the IMWS, these properties are subject of investigation, i.e., (i) the strain behavior of concrete under combined thermal and mechanical loading and (ii) the permeability increase of temperature-loaded concrete and cement paste.
\end{abstract}

\section{Introduction}

Interacting thermo-hydro-chemo-mechanical processes lead to changes/degradation of both the mechanical as well as the transport behavior of concrete with increasing temperature. Regarding the former, a decrease of both strength and stiffness of concrete can be observed (see, e.g., [9, 11]). The strain behavior of heated concrete exhibits a path dependence when mechanical and thermal load are applied simultaneously (see, e.g., $[4,13]$ ). This is attributed to the differing and non-linear behavior of the material phases of concrete (i.e., cement paste and aggregate). Regarding the transport behavior of concrete, numerous fire experiments have demonstrated the role of transport processes such as the advection of water vapor regarding the spalling behavior of concrete at elevated temperatures (see, e.g., $[2,6]$ ). Since dense concrete mixes with low permeability proved to be more prone to spalling, parameters related to the pore structure of concrete (such as the permeability) were identified as key parameters determining the durability of concrete structures 
in case of fire loading. The beneficial effect of adding polypropylene (PP) fibers (see, e.g., [5, 12]), considerably increasing the permeability of concrete at elevated temperatures (see, e.g., [3, 14]), supports this conclusion.

In this paper, the mechanical as well as the transport behavior of concrete subjected to high temperatures is investigated experimentally. Section 2 deals with the strain behavior of concrete subjected to combined thermal and mechanical loading, presenting new experimental results monitoring the longitudinal and radial strains of uniaxial loaded specimens. In Section 3, experimental results for the temperature-dependent permeability of concrete and cement paste are presented.

\section{Mechanical behavior}

As concrete is a heterogeneous material, the different thermal behavior of the two main constituents, cement paste and aggregates, as well as the interaction between the two phases affects the macroscopic mechanical behavior at elevated temperatures. During heating, dehydration of the cement paste results in shrinkage whereas the aggregates expand (the magnitude of thermal expansion depends on the type of aggregate). These strain incompatibilities together with thermochemical damage of the material phases result in degradation of the mechanical properties. The
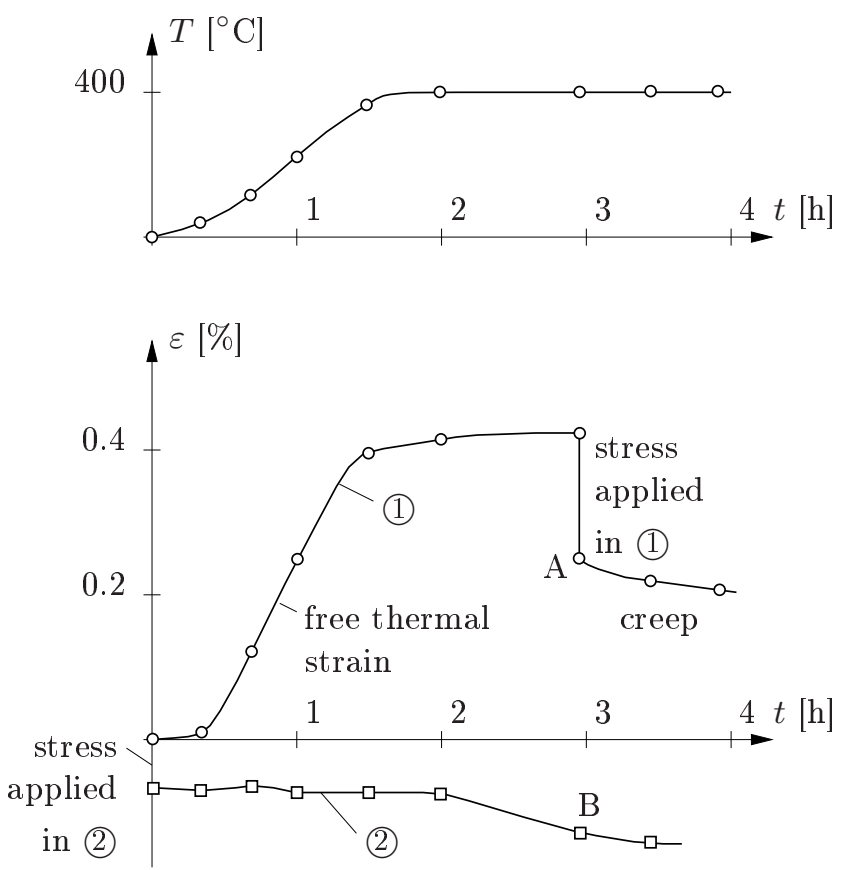

Figure 1: Illustration of path dependence of combined thermal and mechanical loading of concrete [13]: points A and B exhibit the same temperature and stress level (experimental results obtained with $T_{\max }=400^{\circ} \mathrm{C}$ and $\Sigma=0.45 f_{c, 0} ; f_{c, 0}$ : compressive strength of concrete at room temperature)

macroscopic strain behavior of concrete is a combination of the thermal strains of the two phases as well as their interaction. When concrete is heated without mechanical load ${ }^{1}$, expansion of the aggregates induces tensile plastic deformations within the cement paste, the resulting macroscopic strains mainly follow the expansion of the generally stiffer aggregates (see, e.g., [4, 10]). When compressive loading is applied prior to thermal loading, the tensile plastic deformations within

\footnotetext{
${ }^{1}$ The respective strain state is referred to as free thermal strain (FTS) state.
} 
the cement paste are reduced, leading to (i) less degradation of the macroscopic mechanical material properties (see, e.g., [11]) and (ii) a path dependence in the strain behavior, i.e., a different macroscopic strain state compared to the case of heating without mechanical load and subsequent compressive loading to the same extent (see Figure 1).

\subsection{Materials and methods}

In order to identify the described path dependence in the strain behavior for given concrete mix designs (see Table 1), concrete cylinders (100 $\mathrm{mm}$ in diameter and $200 \mathrm{~mm}$ long) were subjected to combined thermal (radiant) and mechanical (compressive) loading. The experiments were conducted at different load levels $s=\Sigma / f_{c, 0}[-]$ (i.e., the ratio between stress and compressive strength at room temperature). The experimental setup is shown in Figure 2. Specimen and steel pistons used for mechanical loading are surrounded by a radiant oven, enabling for simultaneous mechanical and thermal loading. Both longitudinal and radial displacements are monitored by displacement sensors connected to the specimen via temperature-resistant steel rods. In longitudinal direction, the relative displacement between two steel rings mounted to the specimen is recorded.

Table 1: Mix design of investigated concrete without and with polypropylene (PP) fibers

\begin{tabular}{|c|c|}
\hline cement CEM I $\left[\mathrm{kg} / \mathrm{m}^{3}\right]$ & 290 \\
\hline additive (fly ash) $\left[\mathrm{kg} / \mathrm{m}^{3}\right]$ & 50 \\
\hline water* $\left[\mathrm{kg} / \mathrm{m}^{3}\right]$ & $185 / 190$ \\
\hline polypropylene $(\mathrm{PP})$ fibers* $\left[\mathrm{kg} / \mathrm{m}^{3}\right]$ & $0 / 1.5$ \\
\hline siliceous aggregates $\left[\mathrm{kg} / \mathrm{m}^{3}\right]^{\mathrm{c}}$ & 1859 \\
\hline fraction $0-4 \mathrm{~mm}$ [mass- $\%]$ & 36 \\
\hline fraction $4-8 \mathrm{~mm}$ [mass-\%] & 17 \\
\hline fraction $8-16 \mathrm{~mm}$ [mass- $\%$ ] & 34 \\
\hline fraction $16-22 \mathrm{~mm}$ [mass-\%] & 13 \\
\hline aggregate mineralogy: & \\
\hline quartz [mass-\%] & 68 \\
\hline feldspar [mass-\%] & 21 \\
\hline carbonate [mass- $\%$ ] & 11 \\
\hline water/cement-ratio* $[-]$ & $0.64 / 0.66$ \\
\hline water/binder-ratio*, ${ }^{\dagger}[-]$ & $0.56 / 0.58$ \\
\hline initial density* $\left.{ }^{*} \mathrm{~kg} / \mathrm{m}^{3}\right]^{1}$ & $2384 / 2391$ \\
\hline slump* $[\mathrm{mm}]$ & $430 / 410$ \\
\hline air content* $[\%]$ & $1.0 / 2.5$ \\
\hline 28d strength* $\left.{ }^{*} \mathrm{MPa}\right]$ & $+/ 40.7$ \\
\hline \multicolumn{2}{|c|}{$\begin{array}{l}{ }^{*} \text { Left value corresponds to plain concrete, right } \\
\text { value corresponds to concrete with PP-fibers. } \\
\dagger \text { The amount of additives is weighted by } 0.8 \text { [7]. } \\
+ \text { Concrete without PP-fibers is about to } \\
\text { be tested. }\end{array}$} \\
\hline
\end{tabular}

Prior to testing, the specimens were stored under water for 28 days and subsequently, at ambient conditions until testing (approximately $20{ }^{\circ} \mathrm{C}$ and $60 \%$ relative humidity). During testing, mechanical loading was applied first (at load levels $s$ of $0,10,20,30,40,50$ and $60 \%$, respectively and subsequently, the temperature in the oven was increased at a rate of $1^{\circ} \mathrm{C} / \mathrm{min}$ and both longitudinal and radial displacements were recorded, giving access to the longitudinal and radial strains, respectively. In general, three samples were tested at every load step. 

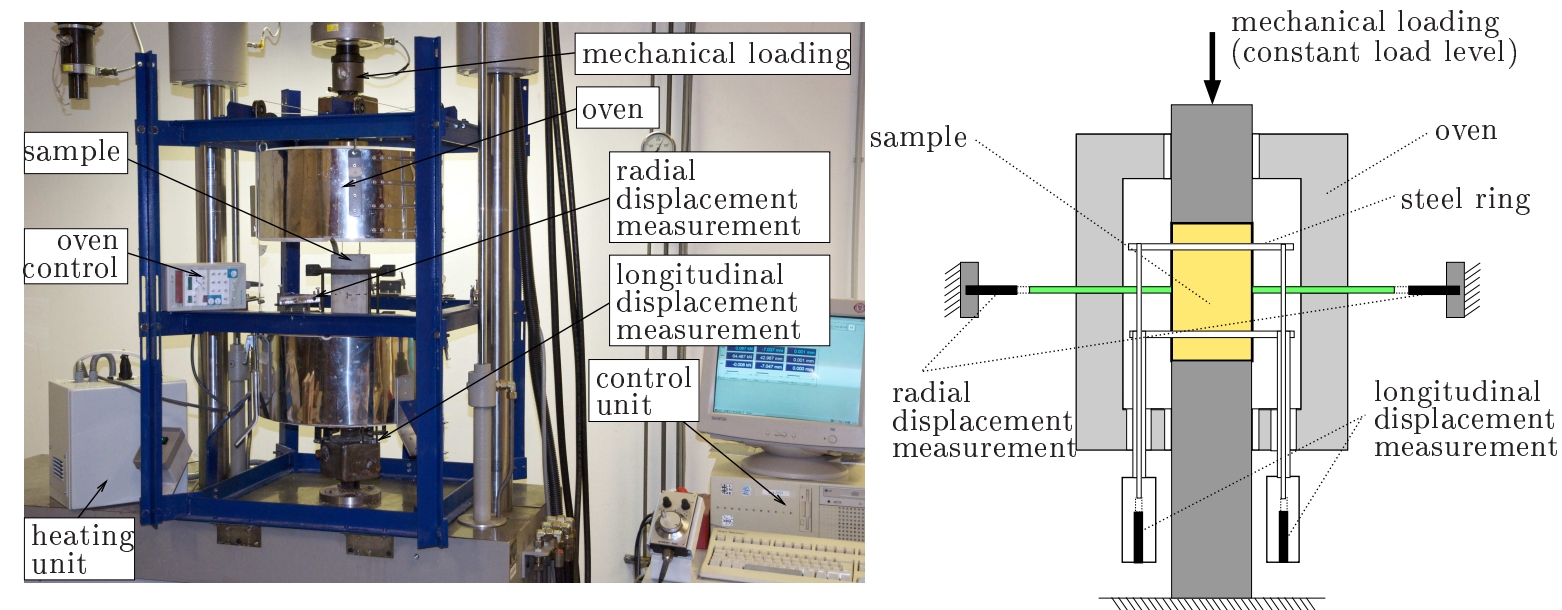

Figure 2: Experimental setup for strain experiments on concrete subjected to combined thermal and mechanical loading

\subsection{Results}

Figure 3 shows experimental results for concrete with PP-fibers, i.e., the longitudinal and radial strains for different load levels. The results for the longitudinal strains are in good agreement with experimental data available in the literature ${ }^{2}$ (see Figures $3(\mathrm{a}, \mathrm{c}, \mathrm{e})$ ). The curves for $s=0$ correspond to free thermal strain $\left(E_{t h}\right)$, having the same magnitude in longitudinal and radial direction. A period of almost constant strain increase up to approximately $550{ }^{\circ} \mathrm{C}$ is followed by a steep increase in strain rate, corresponding to transformation of the siliceous aggregates (from $\alpha$ to $\beta$-quartz which is associated with an increase in volume by $2 \%$ ). Above approximately $600{ }^{\circ} \mathrm{C}$, the strains remain almost constant.

When the specimen is mechanically loaded prior to thermal loading, the magnitude of strains and (with increasing load level) the characteristics of the evolution of strains changes. In longitudinal direction (see Figures 3(a,c,e)), the total strain is smaller for the mechanically-loaded case compared to the unloaded case. This can be explained by delayed elastic strains (in consequence of a temperature-dependent decrease of the stiffness of concrete) as well as plastic strains (in consequence of a decrease of the strength of concrete). The difference between the mechanically-unloaded and mechanically-loaded case increases with increasing load level, resulting even in contraction of the specimen for higher load levels at higher temperature. With increasing load level this transition from expansion to compaction occurs earlier, e.g., at lower temperatures. For $s=0.6$, no significant longitudinal expansion of the sample can be observed since compressive loading and the resulting compaction overshadows the thermal expansion almost completely. Moreover, for load levels $s \geq 0.3$, the specimen failed before the maximum testing temperature of $800{ }^{\circ} \mathrm{C}$ was reached (and the experiment was stopped) since the compressive strength decreases with increasing temperature. At higher load levels $(s \geq 0.4)$, however, the variation in the results increases significant. The strains in radial direction (see Figures $3(\mathrm{~b}, \mathrm{~d}, \mathrm{f})$ ) exhibit a similar behavior as the longitudinal strains. With increasing load level, the difference to the mechanically-unloaded case $(s=0)$ increases. Moreover, the initiation of failure of the specimen can be seen, e.g., in Figure 3(f) by a fast increase of the radial strains. As already mentioned, the failure temperature decreases with increasing temperature.

\footnotetext{
${ }^{2}$ To the authors' knowledge, no experimental results are available in the literature for radial strains.
} 

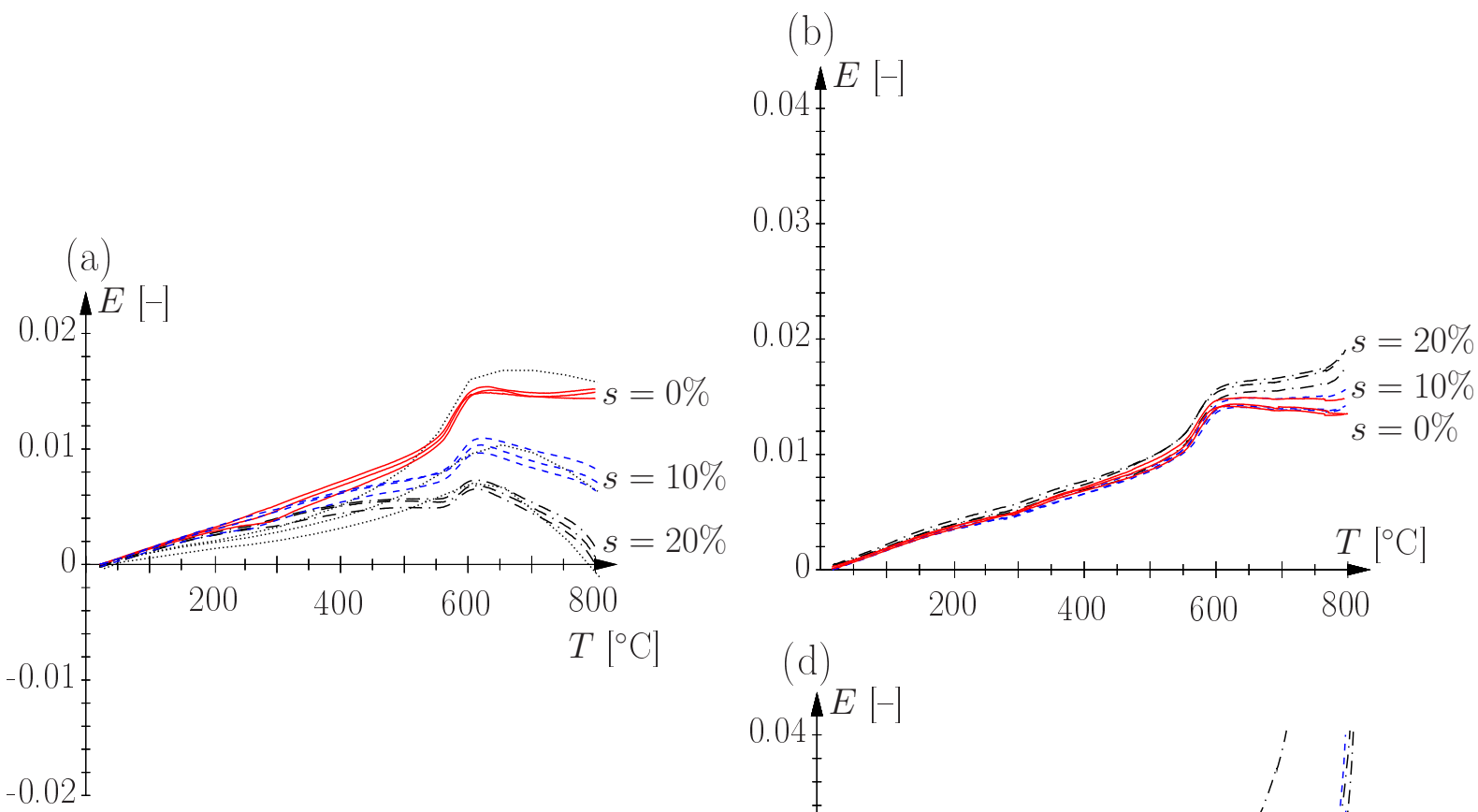

(d)
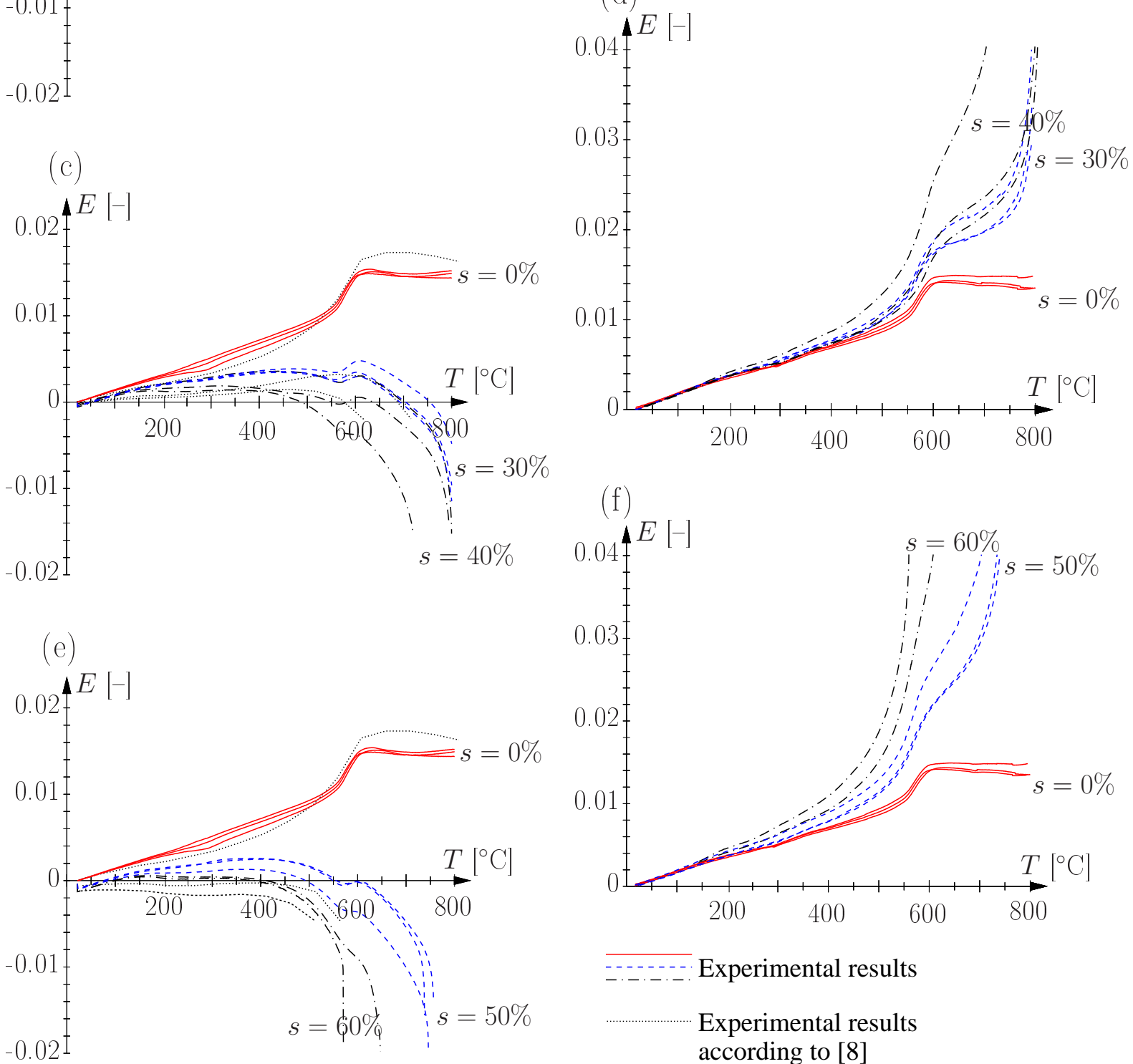

Figure 3: Experimental results for strain $E$ of concrete with PP-fibers: (a,c,e) radial strain for load level $s=0,10,20,30,40,50$ and $60 \%$; (b,d,f) longitudinal strain for load levels $s=0,10,20,30,40,50$ and $60 \%$ as function of temperature 
Based on the directly measured strain $E$ shown in Figure 3, Figure 4 shows the difference between $E$ and the strain at $s=0$ (i.e., the free thermal strain $E_{t h}$ ). In contrast to Figure 3 the average value for every load step is presented in Figure 4. The influence of combined mechanical and thermal loading is directly visible and the obtained results are in good agreement with experimental results from literature [10]. The difference $E-E_{t h}$ increases linearly with increasing load level, except of the results for $s=0.4$ and $s=0.5$ where a considerable variation of the experimental results was observed and, hence, the averaged results must be used with caution.
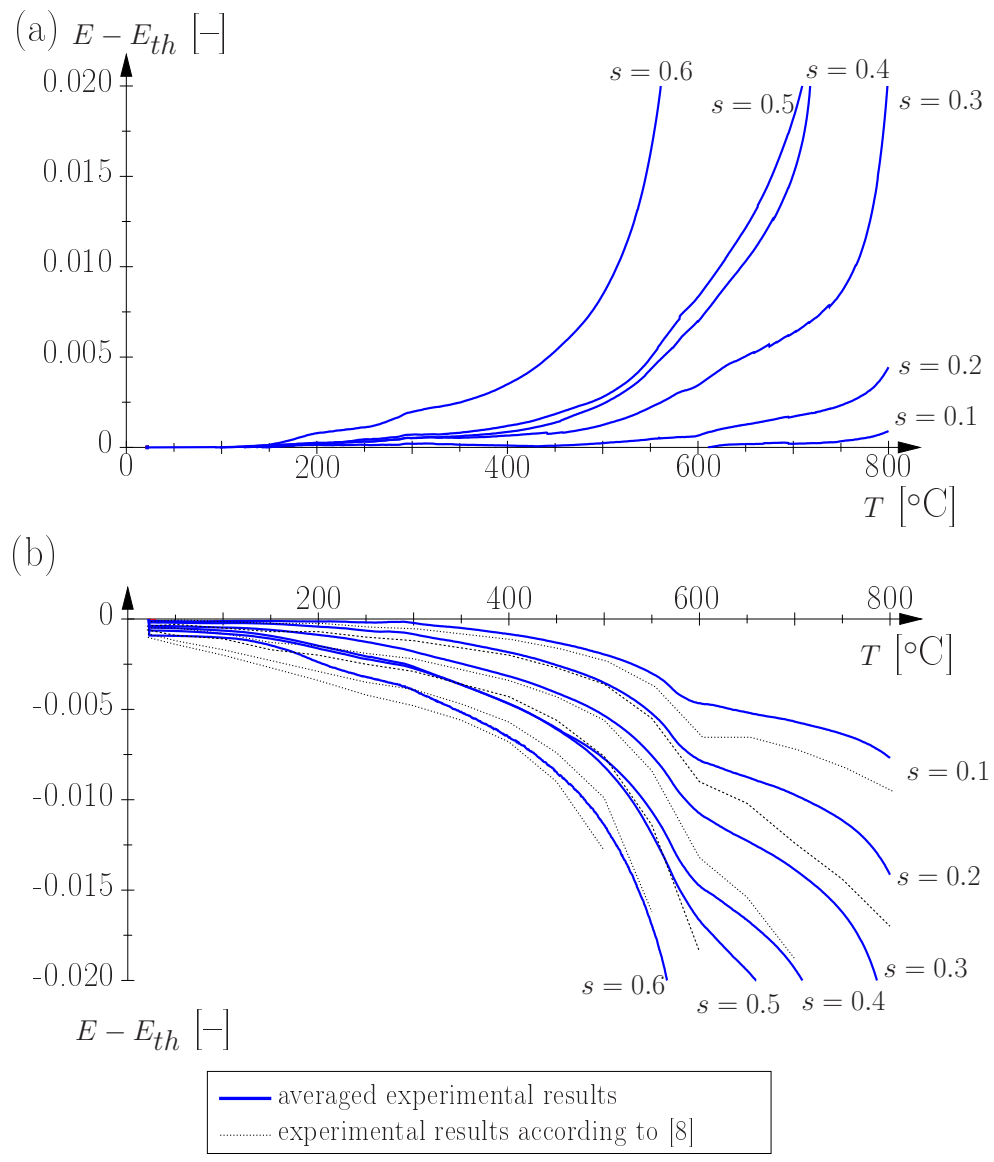

Figure 4: Experimental results for strain $E-E_{t h}$ of concrete with PP-fibers: (a) radial and (b) longitudinal strains for load level $s=0,10,20,30,40,50$, and $60 \%$ as function of temperature

\section{Transport behavior}

As already mentioned, the transport parameters of concrete influence the spalling behavior under fire loading and, hence, the structural safety of concrete structures. The permeability of concrete governs the ability of concrete to advect water vapor originating from vaporization of pore water in consequence of heating of concrete during fire loading. Hereby, the magnitude of pore-pressure built up is directly related to the permeability of concrete and its evolution during temperature loading. In this section, experimental investigations of the effect of thermal loading as well as the influence of addition of PP-fibers on the permeability of concrete and cement paste are presented. 


\subsection{Materials and methods}

The permeability tests were performed on concrete and cement-paste samples with and without PP-fibers (see Tables 1 and 2 for the mix designs). The mix design of the cement paste was derived from the concrete mix design by exclusion of the aggregates (except for the aggregate fraction $<$ $0.25 \mathrm{~mm}$ ) and upscaling of all other quantities to obtain $1 \mathrm{~m}^{3}$ of cement paste. Hence, a PP-fiber content of $4.0 \mathrm{~kg} / \mathrm{m}^{3}$ in the cement paste corresponds to $1.5 \mathrm{~kg} / \mathrm{m}^{3}$ PP-fibers in the concrete mix. For both fiber-reinforced mixtures (concrete and cement paste), monofilament polypropylene fibers (PP-fibers) with a length of $6 \mathrm{~mm}$ and a diameter of $18 \mu \mathrm{m}$ were added during mixing.

\begin{tabular}{|c|c|}
\hline cement CEM I $\left[\mathrm{kg} / \mathrm{m}^{3}\right]$ & $\overline{7782}$ \\
\hline additive (fly ash) $\left[\mathrm{kg} / \mathrm{m}^{3}\right]$ & 135 \\
\hline water $\left[\mathrm{kg} / \mathrm{m}^{3}\right]$ & 355 \\
\hline polypropylene $(\mathrm{PP})$ fibers* $\left[\mathrm{kg} / \mathrm{m}^{3}\right]$ & $0 / 4.0$ \\
\hline siliceous aggregates $<0.25 \mathrm{~mm}\left[\mathrm{~kg} / \mathrm{m}^{3}\right]$ & 471 \\
\hline water/cement-ratio [-] & 0.45 \\
\hline water/binder-ratio ${ }^{\dagger}[-]$ & 0.40 \\
\hline initial density $\left[\mathrm{kg} / \mathrm{m}^{3}\right]$ & $1743 / 1747$ \\
\hline slump* $[\mathrm{mm}]$ & 200 / 195 \\
\hline
\end{tabular}

The concrete specimens used for the permeability tests were produced from large concrete blocks which were cast and stored under water for 28 days. After storage, cylinders with a diameter of $150 \mathrm{~mm}$ were drilled from the concrete block and cut into discs with a height of $50 \mathrm{~mm}$. The cement-paste specimens were cast in plastic pipes with a diameter of $50 \mathrm{~mm}$ and a height of 100 $\mathrm{mm}$. After 28 days of water curing, the cylinders were cut into discs with a height of approximately $30 \mathrm{~mm}$. Prior to the permeability tests, all concrete and cement-paste specimens were subjected to the same heating procedure: heating-up with a heating rate of $1^{\circ} \mathrm{C} / \mathrm{min}$, storage at the target temperature for a minimum duration of $12 \mathrm{~h}$, cooling with a maximum cooling rate of $1{ }^{\circ} \mathrm{C} / \mathrm{min}$. The rather slow temperature increase and decrease was chosen to avoid microcracking due to large temperature gradients within the specimens. The permeability tests were performed for eight different temperature levels and a minimum number of three samples was tested at each pre-heating temperature: 20, 80, 105, 140, 200, 300, 400 and $600{ }^{\circ} \mathrm{C}$. After cooling to ambient temperature, the specimens were built into steel rings, and the lateral side was sealed in order to ensure onedimensional air flow.

The experimental setup and the schematic illustration of the experimental device are shown in Figures 5 and 6 . In order to cover the wide range of the permeability of concrete and cement-paste specimens subjected to temperature loading, the volume of the air reservoir can be varied. Within the experiment, the permeability was determined from the gas flux through the specimen which was determined either from the pressure decrease in the test-chamber volume, $p_{t}(t)$ (see [14] for details) or from the pressure decrease in the reservoir, $p_{r}(t)$ (with constant pressure $p_{t}$ in the test chamber, i.e., at the top of the specimen (see [8]):

1. Decreasing-pressure experiment (DPE):

The pressure in the system was increased to a target pressure between 8 and 9 bar. After stationary flow was established at that target pressure, the air supply was closed and the 


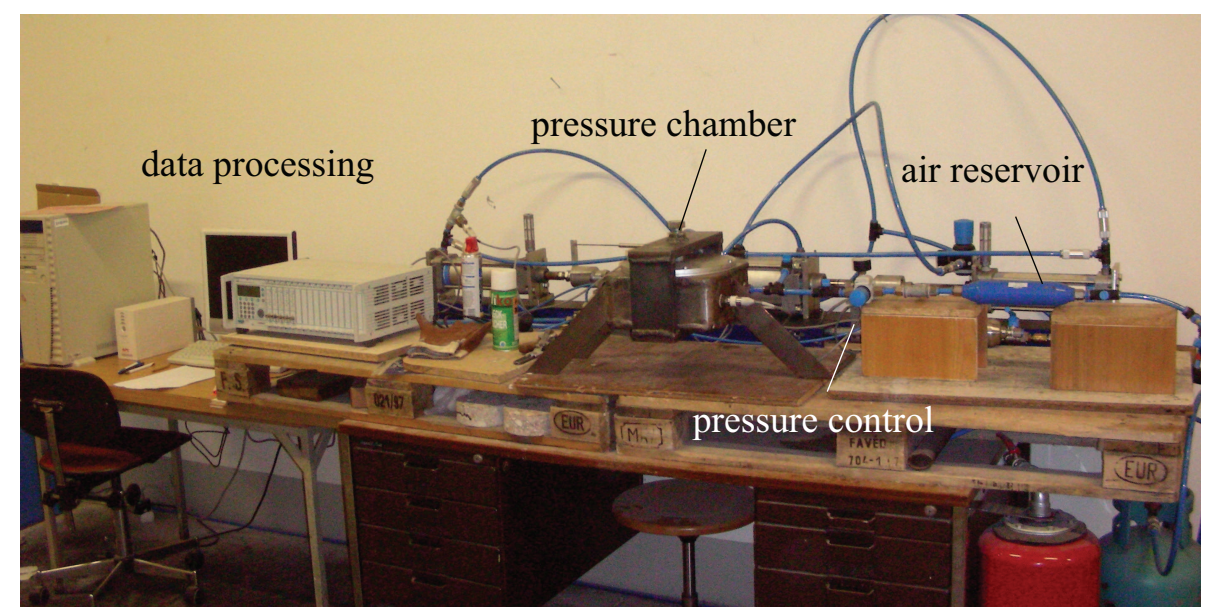

Figure 5: Experimental setup used for permeability tests

test chamber volume $V_{t}, p_{t}(t)$ reservoir volume

$$
V_{r}, p_{r}(t)
$$

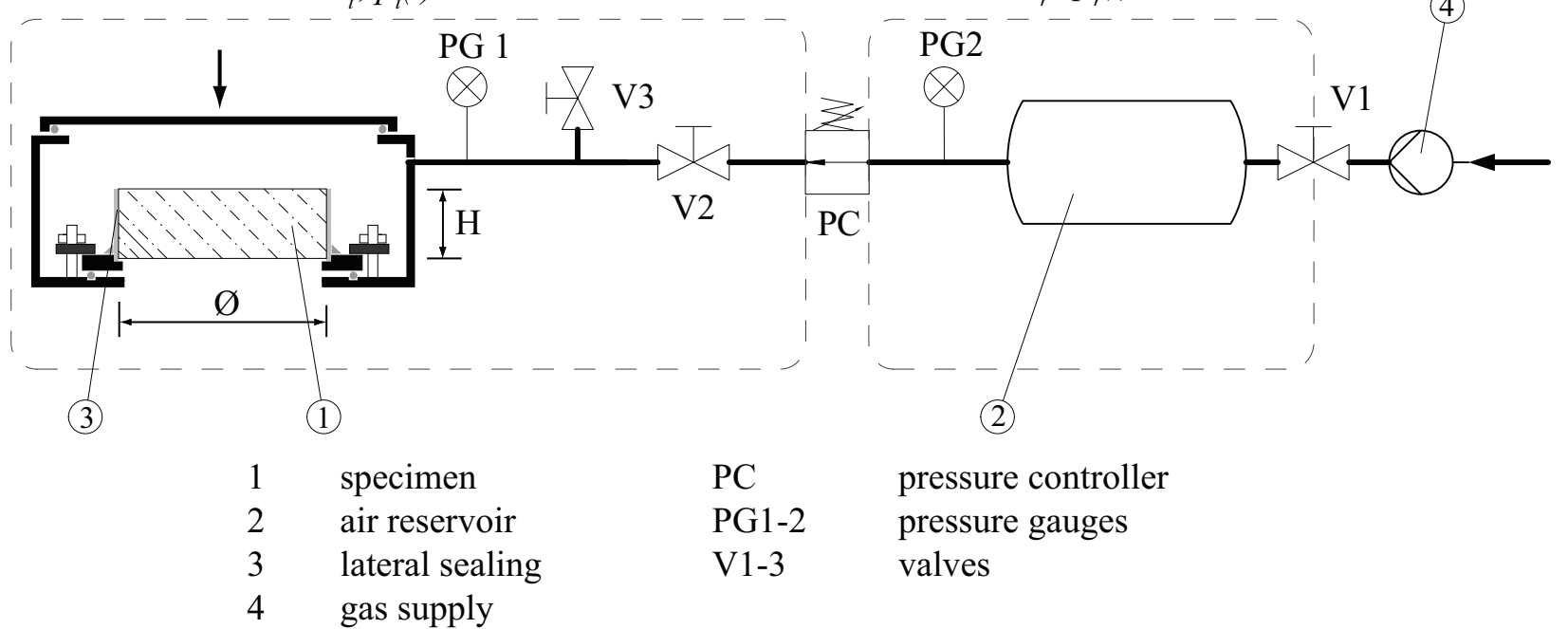

Figure 6: Schematic illustration of experimental device used for permeability tests

decrease of pressure by air flow through the specimen was recorded as a function of time, $p_{t}(t)$. In order to assume quasi-stationary conditions, the pressure drop must occur sufficiently slow which can be actively influenced by the size of the additional reservoir.

2. Constant-pressure experiment (CPE):

Hereby, a pressure of approximately 9 bar was maintained in the pressure reservoir whereas the desired target pressure in the test chamber (ranging from 5 to 8 bar) was set by adjusting the pressure controller. Upon reaching stationary flow conditions, the gas supply was closed and the pressure histories $p_{t}(t)$ and $p_{r}(t)$ were recorded (see Figure 6).

From monitoring the pressures in the system, the flux and, consequently, the permeability was determined as a function of pressure (more specifically as a function of $1 / p$ ) and the intrinsic permeability (i.e., the permeability which is independent of the fluid passing through the specimen) was determined by linear regression (see Figure 7 and [14] for details). 


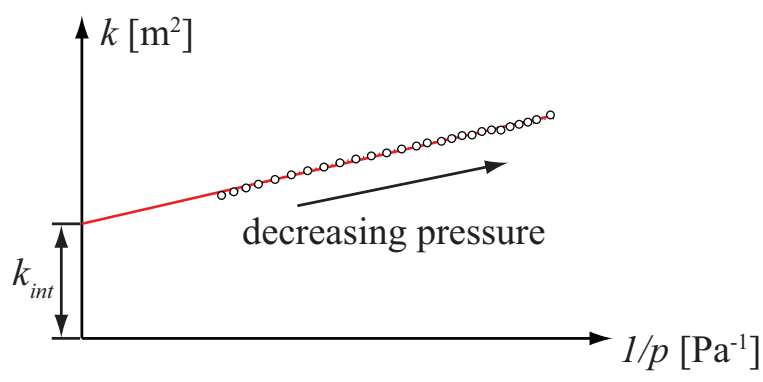

(a)

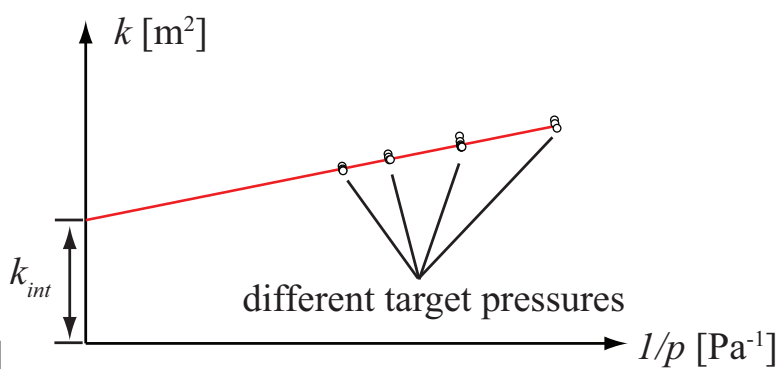

(b)

Figure 7: Illustration of identification of intrinsic permeability from regression analysis of (a) decreasing-pressure experiments (DPE) and (b) constant-pressure experiments (CPE)

\subsection{Results}

Figure 8 shows the residual permeability of concrete and cement paste without and with PP-fibers. At low pre-heating temperatures, no fiber effect is observed, neither for concrete nor for cement paste. In both cases, the respective experimental values are almost equal. However, the permeability of cement paste is smaller than the respective values of concrete. This can be attributed to the existence of interfacial transition zones (ITZ) between cement-paste matrix and aggregates, having higher permeability than the cement paste [1]. The fiber effect can be observed between preheating temperatures of 140 and $200{ }^{\circ} \mathrm{C}$, for both concrete and cement paste. In case of cement paste, this effect is stronger (leading to a larger jump in $k_{i n t}$ ) since the PP-fibers are present in the cement paste only (with a higher amount per $\mathrm{m}^{3}$ of cement paste than per $\mathrm{m}^{3}$ of concrete). In case of concrete, also the (non-permeable) aggregates as well as ITZ contribute to the macroscopic permeability, therefore the fiber effect is smaller for the composite than for the cement paste alone. With further increase in pre-heating temperature, the fiber effect is reduced since temperatureinduced damage of the concrete phases overshadows the effect of melting of the PP-fibers. The extent of this trend, however, is different for concrete and cement paste, with higher differences between cement paste without and with PP-fibers compared to the respective values for concrete. This leads to the conclusion that temperature-induced damage is higher in case of concrete where

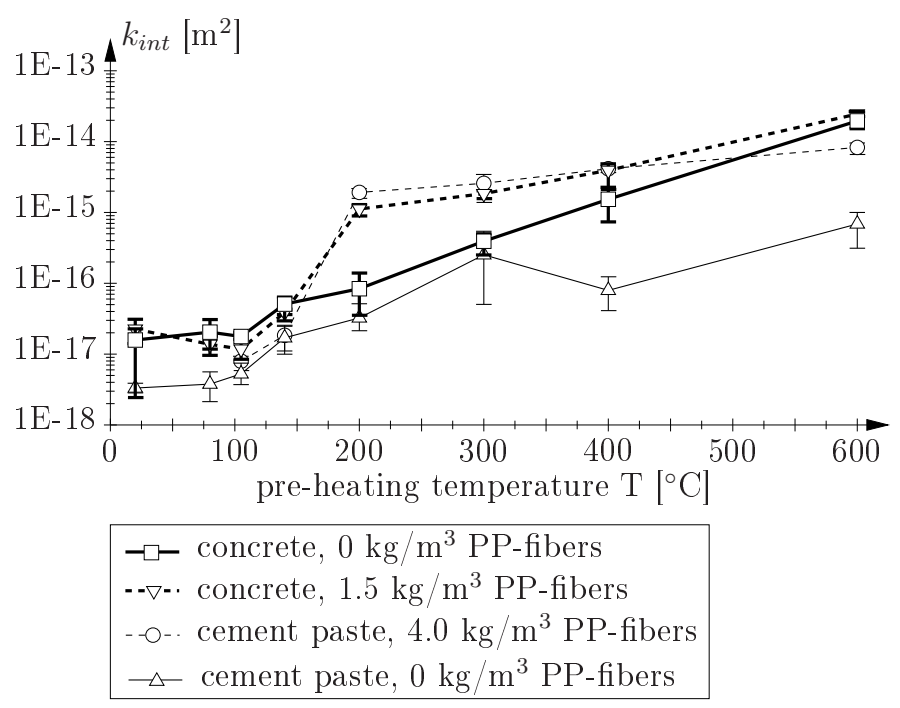

Figure 8: Intrinsic permeability of concrete and cement paste without and with PP-fibers as function of pre-heating temperature (symbols represent average value, lines mark minimum and maximum value) 
strain incompatibilities between cement paste and aggregate contribute to damage of the composite. In case of cement paste, on the other hand, dehydration (leading to an increase in pore space as well as cracking) is the only source of damage, therefore the fiber effect persists to a larger extent.

\section{Conclusions and ongoing work}

Both mechanical and transport properties of concrete are strongly affected by temperature loading. In this paper, the strain behavior of concrete subjected to combined thermal and mechanical loading as well as the permeability of concrete were investigated experimentally.

The experimental strain results showed a dependence on the load level applied prior to thermal loading. The obtained experimental results are in good agreement with results from the literature [10]. The increase of mechanical loading in combination with thermal loading leads to a decrease of the longitudinal strains. A linear dependency between the strain difference $E(T, s)-E_{t h}(T, 0)$ and the thermal strain $E_{t h}(T, 0)$ was observed which is in agreement with observations presented in [13]. The additionally-monitored radial strains complete the strain data.

Experimental investigation of the permeability of concrete and cement paste without and with PP-fibers showed an increase of the permeability with increasing temperature. Moreover, the PPfiber effect (i.e., a permeability jump at the melting temperature of the fibers) was found in both materials, the magnitude of this effect and its evolution with temperature, however, were different for concrete and cement paste.

The presented experimental investigations are interconnected with research activities concerning material modeling of the behavior of concrete at elevated temperatures. In case of the mechanical behavior, a suitable material model (accounting for the heterogeneous nature of concrete) is designed, capturing the experimentally-obtained dependence of the strain of heated concrete on the load level. In case of the transport behavior of concrete, a network model is currently designed, taking information on the size and arrangement of pores in concrete into account. In both cases, further experimental investigation will serve as basis for the modeling work in order to capture the main mechanisms in heated concrete.

\section{Acknowledgements}

This research was conducted with financial support by the Austrian Ministry for Transport, Innovation and Technology (bm.vit) within the KIRAS-project (Austrian security research program) 813794 "Sicherheit von Hohlraumbauten unter Feuerlast" ("Safety of underground structures under fire loading").

\section{References}

[1] D. P. Bentz. Fibers, percolation, and spalling of high-performance concrete. ACI Materials Journal, 97(3):351-359, 2000.

[2] T. Z. Harmathy. Effect of moisture on the fire endurance of building elements. Technical Report STP 385, American Society of Testing and Materials, 1965.

[3] P. Kalifa, G. Chéné, and C. Gallé. High temperature behaviour of HPC with polypropylene fibres: from spalling to microstructure. Cement and Concrete Research, 31:1487-1499, 2001.

[4] G. A. Khoury, B. N. Grainger, and P. J. E. Sullivan. Strain of concrete during first heating to $600^{\circ}$ C. Magazine of Concrete Research, 37(133):195-215, 1985. 
[5] W. Kusterle, W. Lindlbauer, G. Hampejs, A. Heel, P.-F. Donauer, M. Zeiml, W. Brunnsteiner, R. Dietze, W. Hermann, H. Viechtbauer, M. Schreiner, R. Vierthaler, H. Stadlober, H. Winter, J. Lemmerer, and E. Kammeringer. Brandbeständigkeit von Faser-, Stahl- und Spannbeton [Fire resistance of fiber-reinforced, reinforced, and prestressed concrete]. Technical Report 544, Bundesministerium für Verkehr, Innovation und Technologie, Vienna, Austria, 2004. In German.

[6] C. Meyer-Ottens. Zur Frage der Abplatzungen an Betonbauteilen aus Normalbeton bei Brandbeanspruchung [Spalling of normal-strength concrete structures under fire loading]. PhD thesis, Braunschweig University of Technology, Braunschweig, Germany, 1972. In German.

[7] Österreichisches Normungsinstitut. Beton - Teil 1: Festlegung, Herstellung, Verwendung und Konformitätsnachweis [Concrete - Part 1: Specification, production, use and verification of conformity], 2004. In German.

[8] P. Paulini and F. Nasution. Air permeability of near surface concrete. In F. et al. Toutelemonde, editor, Proceedings of the 5th International Conference on Concrete Under Severe Conditions: Environment and Loading (CONSEC'07), pages 241-248, Paris, 2007. Laboratoire central des ponts et chaussees (LCPC).

[9] L. T. Phan and N. J. Carino. Review of mechanical properties of HSC at elevated temperatures. Journal of Materials in Civil Engineering, 10(1):58-64, 1998.

[10] U. Schneider. Ein Beitrag zur Frage des Kriechens und der Relaxation von Beton unter hohen Temperaturen [Contribution to creep and relaxation of concrete under high temperatures]. Habilitation thesis, TU Braunschweig, Braunschweig, Germany, 1979. In German.

[11] U. Schneider. Concrete at high temperature - a general review. Fire Safety Journal, 13:55-68, 1988.

[12] U. Schneider and J. Horvath. Abplatzverhalten an Tunnelinnenschalenbeton [Spalling of concrete for tunnel linings]. Beton- und Stahlbetonbau, 97(4):185-190, 2002. In German.

[13] S. Thelandersson. Modeling of combined thermal and mechanical action in concrete. Journal of Engineering Mechanics (ASCE), 113(6):893-906, 1987.

[14] M. Zeiml, R. Lackner, D. Leithner, and J. Eberhardsteiner. Identification of residual gastransport properties of concrete subjected to high temperatures. Cement and Concrete Research, 38(5):699-716, 2008. 